\title{
Women's Rights in the Light of Standpoint Theory
}

\author{
Panthea Hajisadeqi \\ Faculty of Social and Educational Science; Norwegian University of Science and Technology, Norway
}

\begin{abstract}
Introducing feminism opened up a new era for those whose voices have not long been heard. "Women" as half of the world's population, who naturally existed since the source of creation, becomes the term central to this article. Controversies by debaters highlight the elements and the effects of supremacy upon men who dominate and women who are dominated. Through a descriptive research design, this study pursues reviews of careful analysis and arguments made by thinkers ( since mid-20 $0^{\text {th }}$ century) in terms of the significance of women's knowledge of their own needs, interests and their conscious control over their own life and social activities. The controversies introduced here are specifically introduced under the title of Standpoint theory. Arguments would broaden the target readers to even those who unconsciously contribute to marginalizing the minorities. Here by minority, I imply women as not being minors but rather considered and categorized as minors by masculine society. Women form half of the world's population; however, they are considered second-class with unequal rights. The literature selected is a list of arguments introducing those differences involving gender, and discusses how female citizens need to attempt to push the boundaries and to cry out their voices through the acknowledgement of their own rights, potentials and interests.
\end{abstract}

Keywords: knowledge, dominance, marginalize, identity, subordinates

\section{Introduction of Standpoint theory and its roots in feminism}

Standpoint theory first introduced by Sandra Harding brings about fresh perspectives into the feminism's contribution to science, philosophy and political discussions in our era. She argues that feminism must focus on every aspect of natural and social orders. In this path, the key questions concerning nature of knowledge, objectivity, rationality and good scientific method are being introduced. As a result, the central question of this article becomes "whose knowledge matters?". Harding's controversial point of views shape the core of article's structure, and other philosophers' debates link to hers. Feminist movement has taken a long challenging journey to respond to basic needs of female gender. History has witnessed women's discrimination imposed by institutional and political system of law operating by male figures and even females themselves. Every single part of this thick wall had to be relocated for women to achieve the platform they stand on today. Legislative laws have passed, many organizations have been restructured, numerous demonstrations have taken place so that barriers were partially removed, the ground for the women's studies was built, cultural studies and several humanistic studies were funded to eventually illuminate and acknowledge their status in real world. It is a long process starting from survival to gaining qualifications, becoming more visible, reaching 
the balance and maintaining it. Formerly, it has been accepted that philosophy of science, epistemology and philosophy have to be kept distinct, while Harding (2004) insists that feminism is not to be restricted to social and political issues. She claims it to involve every aspect of natural and social orders including knowledge, objectivity, rationality, and good scientific method.

Why standpoint theory? As reflected in "A Socially Relevant Philosophy of Science? Resources from Standpoint Theory's Controversiality", standpoint theory is thought of in a number of different ways. One of the strong points of standpoint theory is that it has been thought of as different philosophical terms. It's thought of as an epistemology that is a theory of who can produce reliable knowledge and how knowledge should be justified; philosophy of science of what best practices and goals for scientific research should be. Moreover, it's thought of as a sociology of science that looks at the particular social conditions and creates different kinds of knowledge. Therefore, it is what makes standpoint theory as a methodology of how to go about doing research (Harding, 2004).

Furthermore, standpoint theory is truly thought of as having a very particular historical lineage. Harding (2004) takes one of Marx's concerns regarding class system. Marx suggests that in order to learn about how class system works, it is best that we look into workers' lives rather than starting from lives of the elites of the day. Feminism took this as a pattern and transformed it to be applicable to its own areas of concern. As a result, standpoint theory introduced by Harding, functions more than a sole theory and turns into a method of a theory, a philosophy of natural and social sciences, an epistemology and a methodology in its guidelines to future feminist research (2004). The reason is that feminism moves far beyond concentration on women's issues and spreads its wings on participation of women in scientific and social improvements that humanity would benefit.

In order to discuss concerns and participation of women, a proper definition of being a woman sounds beneficial. Judith Butler in Gender Trouble (1990) argues that world defines women according to their sex, while there is another dimension which rather defines a human's identity, it is gender and the person they become. To determine identity, the feminist theory needs a language that can fully and adequately represent this gender. Women as second class have long been misrepresented by social norms and laws and it becomes necessary for them to find their voice and to be heard by others. This article uses the term feminism as a movement which attempts to echo the sound of women as identity, the identity that is not limited to sex, but rather the gender that takes several diverse dimensions from person to person. This identity does not define and limit women to certain characteristics. It both determines that women share common characteristics that implies their activities within the group and gives the individual identity to every individual self. Here womanhood becomes something beyond a feminine sex, something which takes a free and flexible identity to perform free of physical limitations.

As of feminism's strong thinkers, Simon de Beauvoir has not been the first, but the one whose voice has been louder than other thinkers of her own time. In opening up the arguments that are marked by Beauvoir, it would be appropriate to start with the question "What is gender?". Beauvoir in "The Second Sex" (1949), believes in humanity and terms masculine and feminine genders are two poles of that. Two poles which are considered symmetrically only on paper, but in reality, masculine represents positive and neutral, whereas feminine represents negative. She further clarifies arguments between male and female gender over a certain topic due to their gender differences, as a woman thinks like this because she is a 
woman, and this debate goes on as putting the woman in weaker position for her opinions based on gender. This makes women as always wrong and men as always right. Beauvoir however claims that it would have been appropriate that woman could respond to men's contradictions to women's opinions due to their masculine gender. For centuries, masculine has been defined as the absolute human type and feminine is imprisoned within the limits of her own nature. Beauvoir goes on saying that those women who wished to gain respectable social status were misled by pretending to have masculine characteristics or using the social status of a maledependent family member like husband or father. On the other hand, men considered their bodies as in a direct and normal connection with the world, while women's body is "a hindrance, a prison, weighed down by everything peculiar to it" (p. 3).

To provide clearer image of how women are being assumed by men, Beauvoir quotes from Aristotle, "The female is a female by virtue of a certain lack of qualities"; "we should regard the female nature as afflicted with a natural defectiveness." In continuation Beauvoir quotes from St Thomas for his part pronounced woman to be an 'imperfect man', an 'incidental' being (p. 3). This would clarify the definition of gender up to the period that Beauvoir lived and still a lot of women are suffering from this traditional perspective from the male-dominant thinking. One has to admit that a long journey has passed and still there is more to achieve. Rights of women clearly challenges the dominant notion of women as subordinates who in most cases are not even aware of themselves being dominated. Apart from masculine gender, religion, social and political system play a significant role in sustaining this oppression upon women.

In a more practical objective, Harding in "The feminist standpoint theory reader" (2004), addresses feminism as "a research in a wide range of projects" which challenges conventional feminism as a political movement. Formerly, feminism has been viewed as "a political movement and according to the conventional view", and "politics can only obstruct and damage the production of scientific knowledge" (p.1). Standpoint theory emerging in 1970s \& 1980s, highlights the notions of human nature and the ideal society which feminism portrays. In other words, standpoint theory unveils the value of oppressed groups and, as a result; introduces the notion that there is no more clear-cut distinction between fields such as epistemology, political strategy, methodology, and feminism as if they are part of feminist social theory. It strengthens the oppressed groups and develops an "oppositional consciousness" (Collins (1989) \& Sandoval, chapter 14) as quoted by Harding. Furthermore, standpoint theory equips feminism (formerly known as a political movement) with more research dimension and scientific knowledge, yet free from social and political elements. In addition, Harding in her article "A Socially Relevant Philosophy of Science" (2004) clarifies research concerning women's rights to be started by women who are struggling in a masculine universality. The research would be enchanted with a strong objectivity that is needed to investigate the core of the issues and to introduce the requirements. These oppressed individuals have the power of objectivism to bring to attention those elements that the dominant groups are unable to recognize or confess to. Standpoint theory will give the tribune to this marginalized group (gynocentric biased) to send their voice to the dominant white males (androcentric biased) who benefit more. This way of doing philosophy of science makes science a humanity.

According to Harding (2004), philosophy turns science into the kind of enterprise that is conducted by great artists, great poets and great musicians and they get insights from who knows where. It is their individual creativity, their connection with the universe in some mystical inexplicable way that permits production of important new knowledge. As a result, 
this article will take on three controversies introduced by Harding as the key elements and investigates the role of women in social skills and scientific research. It also brings about notions highlighted by other philosophers and thinkers like Beauvoir, Marx and Williams who share the same viewpoints and keeps focusing on the question "whose knowledge matters and how". According to Harding (2004), women's movements must seek the knowledge for women as oppressed group. Women for long have been the object of the research disciplines in relations to whatever were supposed to be their concerns and needs, still could not have a hand in defining those disciplines. Harding argues that women needed to become the subject of knowledge in various diverse collectives.

\section{The First Site of Controversy: Exploring the role of women in discovering and raising questions regarding their own concerns and interests}

Women's issues matter to women in science and technology fields, and in society at large.

I have suggested how they also matter to the sciences a such, .... We can at least hope that the gains made in institutional practices and in the growth of knowledge during the last three decades - the result of positive interaction between women's movements and scientific and technological institutions - will persist. (Harding, 1998)

Harding in "A Socially Relevant Philosophy of Science? Resources from Standpoint Theory's Controversiality focusing on Standpoint theory" (2004), views the logic of scientific research differently as it concerns philosophical role of the science. She explains that scientific research process gets initiated by questions and expectations of those who take the most benefit out of the discovery. However, the context of discovery is better be left free of all kinds of regulatory controls and that is where philosophy of science steps in. This side of doing philosophy of science makes science a humanity, the kind of enterprise that artists, poets and great musicians would lead. Without philosophy of science, only funders and sponsors get to ask the origins of scientific questions and as a result, those in need would be left out of the circle. Women's movement challenges the policy makers for excluding women, their interests and their perceptions of good life. It debates assumptions and systems that underrepresent the scientific potentials of women leading to lower numbers at higher levels in technological and scientific fields.

Harding in her feminist standpoint theory specifically argues this theory to have its history in Marxian thought. Formerly, the research within the field of feminism which sanitizes it from Marxism, either falls into empiricist, poststructuralist terms or creates misleading features. She; however, claims that the research focusing women's concern leaves valuable influence on theoretical, methodological, and political thought in general. Taking standpoint terminology in general, Harding (2004) clarifies that "standpoint theory is a kind of organic epistemology, methodology, philosophy of science, and social theory that can arise whenever oppressed peoples gain public voice" (p. 3). As a result, one has to admit that social orders convey different definitions from the perspectives of different groups. Marx focuses on class differences and Harding reflects on gender studies in the light of standpoint theory. Therefore, it becomes the concern of one or some groups of people that each philosopher has been focusing 
on, this oppressed group, which is considered out of the ring, that is not original and is illfitting.

Going back to the concept of women as the Other, Beauvoir (1949) in "The Second Sex" talks about the concept of self-consciousness as debates by Hegel. She remarks, "following Hegel, we find in consciousness itself a fundamental hostility towards every other consciousness; the subject can be posted only in being opposed - he sets himself up as the essential, as opposed to the other, the essential, the object" (p. 5). In this context and focusing on the concept of women as racial minorities (the Others), they never get to ask about their own concerns and expectations especially in areas relating to women's body, health, reproduction where they received very low attentions and insufficient fund. How come that male dominant science decides and produces the questions that concern female societies including women of several different needs and concerns. Male scientists and politicians assumed their own concerns and questions to be human's needs in general and this type of relationship between science and society, between corporations and people have long been the dominant system of governing the states.

However, and as Beauvoir in "The second Sex" (1949) clarifies, women and men are like two components that are both necessary in forming a certain totality due to their biological relations to each other and their reproduction. Beauvoir offers women in their path in seeking more legal rights can break into workplaces, engage in cultural activities or take on some of what men held as a privilege or even domain. That is how they can achieve more legal rights that truly support them or as Harding points out, women can add several diverse dimensions to the practicality of science that lacks without their active participations. It is also highlighted by Beauvoir that women and men are first human beings who have different dimensions in terms of body, clothes, interests, occupations and in the road to success, women have to accept their feminine potentials and weaknesses and that they are not supposed to personify themselves as men to become accepted and visible. Ignoring feminine characteristics does not add to the value of women, but rather makes them subordinates in relation to men. It puts women in shadows where they seek the protection and support of subject (i.e., Men). Therefore, the acknowledgement of being a woman matters for women in order to open the path to the investigation of their own interests and needs.

As opposed to the dominant notion of male mindset, standpoint theory brings to our attention the notion that those who are affected have higher rights in posing scientific questions and in building the ground for the research process. Harding in "Women, Science, and Society" (1998) points out that stronger participation of women in science would contribute to improvement of the science itself and the cause of women in general. Women as pioneers would turn to become role models to encourage the entire gender's endeavors. The achievements of women like Marie Curie, for instance, have inspired future generations in developing scientific knowledge and research. Such scientists have relocated the borders created by scientific and technological institutions in excluding women and instead have given some credit for increasing social justice in empowering women's social roles. This scientific advancement has benefited both women and the society they live in. It has trained several skilled, highly motivated female individuals in taking roles in fulfilling projects that benefited humanity.

In the same article regarding standpoint theory (1998), Harding highlights that women's participation in the research, for instance concerning women's health issues, adds to the 
legitimacy of the project in the public perception. The lack of objectivity has been one of main issues and challenges in scientific research where women were deliberately excluded. However, welcoming their active participations would send the message that objectivity and effectiveness are present there. This would therefore prove that all aspects of the case are scientifically considered. In medical science and where women are actively enrolling as researchers, taking women's health issues into considerations would not only benefit female gender, but also the whole family members and society would be positively affected due to the fact that women bear diverse responsibilities as scientists, active social members and housekeepers. Women in the west and the developing countries show their enhanced roles in health care departments, in the offices, in households and they contribute to the objectivity and effectiveness of the projects.

Consequently, active participation of both male and female taking different roles would add to advancement of the gender-based knowledge. Women have great potential (due to their traditional roles) in spotting certain patterns in children's illness, environmental issues in the neighborhood, home appliances problematic functions and many other things that men might not notice due to their different potentials and roles. In societies where women are active in agriculture, animal husbandry or forestry can constantly bring experience and updated information to repositories that provides more valuable knowledge to their social conditions and eventually development of their environmental status. Thus, women's enrollment would bring several diverse dimensions to the scientific projects and add to the credibility of research. This does not; however, underestimate men's roles in the projects, but double-emphasizes the necessity of cooperation between the two.

\section{The Second Site of Controversy: The significance of staying withing the group}

The second site of controversy determines the importance of staying within the group.

For centuries, it has been individuals who were the agents of knowledge and political actions. However, the second source of controversy for standpoint theory by Harding (2004), brings about the idea that this honor is for the group of people, the poor, disabled, minorities, and in this specific case women who are the subjects or agents of knowledge concerning their own gender. Of course, each individual has their own knowledge about different subject matters, and it is unique, but people of the same group share similar experiences because of the common opportunities, obligations and duties that they encounter. Meanwhile, each individual has specific characteristics and knowledge which can be shared within the group due to the similarities. Beauvoir in The Second Sex (1949) points out a similar argument that women have always been around, and they have always been subordinated throughout the history. She explains that they did not own the means to organize themselves into a unit in order to face the other significant unit. The problem is that women have attached themselves to men (i.e., father or husband) through the house works, economic conditions, social standings more than they attach to other women to form a unit of their own.

Beauvoir further claims "women do not say 'We', except at some congress of feminists or similar formal demonstration; men say 'women', and women use the same word in referring to themselves. They do not authentically assume a subjective attitude" (p. 6). She furthermore seeks the root of the problem in the fact that women attach themselves more to the males through residence, housework, economic conditions social status than to other women. As a 
result, they are unable to organize themselves into a unit like the way for instance proletarians, American Negroes or Jews did within their groups. Women accept the label that is received through fathers or husbands; if they are white, bourgeoisie, etc. Being a member of a unit creates a sense of possession, a dream to achieve certain things, since the members share more or less the same experiences, needs and sufferings. Nevertheless, women cannot dream of exterminating their oppressors due to the fact that they are bound to men, and they find their own identities in relations to the males.

All Raise is a group of female business founders and funders who jointly have established an organization to empower women's capabilities in technological fields. Pam Kostka, one of the founders, answers to questions posed by Forbes (www.forbes.com). "What problem does All Raise solve for women in tech? How universal are these problems?". In response, Kostka defines All Raise as a female-leading organization to pursue women's success in a tech culture environment. This formation is the result of a highly demanding world that pushes women to work harder to respond to the demands of being an entrepreneur or a venture capitalist. As a result, a woman is left out of deals and has to work longer and harder resulting to her acting less effective. All Raise aims at offering guidelines, support and access to their network that leads to compress the cycle of work and to form more women-led companies funded by women. This, of course, does not exclude men from the group and men gradually join in to participate in creating a very powerful picture of women supporting each other in a male-dominant technological world. The image and message that it sends to the world introduces productive female investors, producers, inventors welcoming people regardless of their gender. In order to be successful in it, women are being invited to join in to share their talents and to act productive. This is a recent example of the urge for women to form their own group and pursue the topics which are their concerns.

It would be appropriate to relate this site of controversy to a core element in The Second Sex, where consciously analyzes the perception of men whose body makes sense in itself, while woman is just sex in its subordination to man. That is where woman's positions are being reduced to the other being. That is why women have to form their own group to empower, redefine themselves. They gain the potential to show their social capabilities and independency. She continues that "that no group ever sets itself up as the One without at once setting up the Other over against itself" (p. 4). This categorization would create sense of (following Hegel) 'hostility, unfriendliness or fundamental opposition' between the groups as subject and object where men consider themselves as superior, subject, essential versus women as object or inessential. Beauvoir (1994) claims that the other has to regain its position as one and in order to do that this group has to first acknowledge this inequality happening due to inequality of numbers. However, woman as half of the population is not the minority. What has happened here is the weak social participation of female due to pressures imposed by the dominant male group. That highlights the enrollment of single female individual in the group to clear weaknesses and rebuild a new picture of itself. Beauvoir (1949) emphasizes that women never brought about the change because they could not learn from history as other minorities like negroes, for example could. As a result, spotting the failures and learning from the past would guide them in their policies for the future. Beauvoir discusses that women never said "WE", since they have gained only what they have been given by men. The seeks the reason in the fact that they have been unsuccessful into organizing themselves into a unit. They never had the sense of belongings to the group as what proletariat did. Women used to find protection in the shadow of their male dependency. 
Going back to Harding's second controversy, one can easily figure out that first and second controversies are interrelated. The first site emphasizes on the necessities of women's participation in revealing their own concerns and interests, so that research and industry would build their questions based on the claims that women make in regard to the projects related to female body, psychology, health and education. Second site of controversy points out the significance of women forming their group and participating actively in group on areas which defines their destiny. Harding (2004) in her debates regarding standpoint theory, defines the term feminisms as in the plural, since she meant it for different groups of women and men in different places, in history and around the world. These groups are different from each other, but they all share their concern that is to produce sources for women and to enable them to take better control of their lives. In the next chapter, the third site of controversy adds extra dimension to these two as clarifying that social participation of the group would construct our perception of the world and our strategies toward it.

\section{The Third Site of Controversy and its relation to the concept of 'Determination' used by Raymond Williams}

The third site of controversy discussed by Harding in "A Socially Relevant Philosophy of Science? Resources from Standpoint Theory's Controversiality", defines constructivism in the light of standpoint theory. Social constructivism mainly argues that knowledge is socially constructed, but standpoint theory has a different kind of constructivism. It discusses that the way we interact with natural and scientific environments both enables and limits our knowledge. It does not ascertain our knowledge, still it is relevant to what we can know. The social group that we are a member of shapes how we see the world, how we communicate in it, what makes or does not make sense to us, and we stand in a specific position to see the world with that perspective. Therefore, members of the same social group who share the same standpoint, more or less (not necessarily exact) share the same viewpoints. In other words, it gives us opportunities that we might not have achieved otherwise.

In case of feminism, women have not been historically treated well and not equal to how men have, and the social group they belong to suffer from the societal inequalities. As a result, this equality becomes the core of their standpoint, shapes their viewpoint to the society they live in and have impacts on their relationships to other groups of the society (Harding 2004). Subsequently, women as the members of a less powerful group have stronger objective perspectives towards the topics that have impacts on their personal and social lives. Therefore, what we know highly depends on what group we belong to. This is both liberating and limiting for humans. It shapes how we approach social elements, but it also restricts the comprehension of diverse dimension of the same elements. Relating group differences takes us to Marxism with a clear difference that Marx highlights the aspects related to proletariat due to economy, while feminist standpoint theory focuses on gender issues. In other words, Marx emphasizes on knowledge of the social classes (factory workers vs factory owners or power against rich) matters in battles with norms of capitalist institutions (Williams, 1977), whereas feminist standpoint theory focuses on necessity of the knowledge of women as the oppressed group in their resistance to limiting social and political male-dominant ruling system. According to Harding (2004), it becomes the core characteristic of standpoint theory as "a kind of organic epistemology, methodology, philosophy of science, and social theory that can arise whenever oppressed peoples gain public voice" (p. 3). 
What Marx and Harding share is determination of a power or a law which socially structures the outcome or what we specifically focus on "the oppressed groups". As pointed out by Williams in "Marxism and Literature", Marxism introduces determination as "the setting of limits" (p. 87). Determination is the translation of the original German word "bestimmen" as introduced primarily by Marx. However, it is not only the setting of limits as Williams defines determination of, but it also takes a positive dimension when, in practice, it applies to the exertion of pressures against limits. Therefore, determination in this context is interpreted as to determine and to be determined to do something willingly and purposefully.

In other words, negative determinations that impose restrictions on certain social classes become the initiation of the formation of opposition in fighting against the same determinations. It is a social process which might start with individual experience but is consequently led to a cause or pressure against the limits. As a result, society is not primarily a "dead dusk" which only restricts social and individual development, but it also facilitates the formation of constitutive process as the result of powerful pressure. In continuation of the subject of determination, Williams (1977) discusses the term overdetermination as "an attempt to avoid the isolation of autonomous categories but at the same time to emphasize relatively autonomous yet of course interactive practices" (p. 88). He ascertains that overdetermination happens to be more positive and useful in spotting the multiple forces rather than the isolated forces of techniques of production. It also contributes so well to understanding historical situations and the authentic complexities of practice. In the relations between autonomy and variety in any society, both the relative autonomy and the relative unevenness of different versions of practical consciousness clearly influence progression in the way of pressures and limits or what is called determinants.

Williams further adds “As with 'determination', so 'overdetermination' can be abstracted to a structure (symptom), which then, if in complex ways, 'develops' (forms, holds, breaks down) by the laws of its internal structural relations" (p. 88). This would take us back to the beginning of this chapter regarding Harding's definition of social constructivism that the system constantly enables and produces certain laws which both empower and limit our perspectives toward a certain concept. It gives dimensions and knowledge to what we should know, and we are unable to acknowledge without it. However, it still limits our visions and developments in some other areas. This would lead the argument to Harding's concern regarding illiteracy. In a conversation with Harding called 'Starting from Marginalized Lives', Hirsch E. \& Olsen G. A. (1995), writes Harding's viewpoint about the necessity of 'literacy' in doing research and clarifies the reason why Harding struggles against 'illiteracy'. Harding explains that the word science has gotten identified as emerged three or four hundred years ago by Western tradition with its roots only in Aristotle and Greek societies, and it excludes other traditions like Islamic societies. As a result, when we speak of science, we are practically using a non-universal language by excluding non-western traditions. The same applies to the West and 'philosophy of science' voices which does not happen to be universal when it appears out of a certain historical tradition and not the whole universe. In the same conversation, she remarks:

Look, there's another context in which those who are the best educated science people in the West are illiterate about the very nature of their own scientific project and of the possibilities for developing in more progressive ways; we think that the way we've got it is the only way it could be. (p. 201) 
Harding in the same interview in 1995, picks herself as an example, she as a philosopher from Western philosophy who knows the Western tradition so well, has the opportunity to turn critical lenses on and to try to learn and she obliges herself to do so. She has the potential to criticize the tradition she comes from with the knowledge she has, and she sees that as a resource which would benefit the victims of the West. In addition, she points out about male feminists like John Stuart Mill, who uses his own platform in thinking about the disadvantages of growing up male. Mill claims the words to be whispers of his deceased wife, but Harding would give the credit to Mill for spreading out the words and publishing them, since a few men would do that. Mill develops a particular view that seems to include both male and female position. Harding in Starting from Marginalized Lives decides that men have the possibility to use their social location in order to make a of list several issues relating to themselves that can distinctively contribute to feminist mindset. This type of contribution is something that women will not be able to make due to their physical difference, historical difference, and different access to social patterns and practices. Therefore, we can assume that the knowledge of the dominant as the knower as well as the knowledge of the dominated, who has the most concerns, can assist together in claiming the rights of dominated.

Summing up the arguments of Harding and Williams in this chapter, one would admit that the knowledge we achieve empowers us in certain ways, however, certain areas would be left out of the research. As a result, and in case of women's concerns regarding their rights, it will not suffice to look at the subject from one point of view, but researcher has to include all aspects of human needs as historical, social, political, psychological, scientific as well as philosophical to provide a more literate voice that considers all aspects of women's affairs. In this respect, the knowledge of both dominant and dominated, determined and determiner, powerful and oppressed would be required to pose the right questions, to express human concerns and to respond to the needs of female citizens.

\section{Conclusion: Whose Knowledge Matters?}

Women as the subordinates have been the subject withing the field of philosophy for decades. The reason behind this is the fact that men have had more social power and their views had received more validations. On the contrary, women as the marginalized group had to learn to be bicultural that is to pass in the more powerful gender to survive. Beauvoir in The Second Sex gives a clear picture of women's status of her era:

it is an easy road; on it one avoids the strain involved in undertaking an authentic

existence. When man makes of woman the Other, he may, then, expect to manifest deep-

seated tendencies towards complicity. Thus, woman may fail to lay claim to the status of

subject because she lacks definite resources, because she feels the necessary bond that ties

her to man regardless of reciprocity, and because she is often very well pleased with her

role as the Other (p.8).

Also, one cannot ignore the fact that women themselves for so long sought out their comfort and safety in the male protection. We all make choices, and we have to accept that it is the complicity among men and women that maintains the results. Women might choose to take 
smaller roles and fewer responsibilities that might create significant distinction between men and women. That is what makes men Self and women the Other.

Harding (2004) adds new practical dimensions to women's movement by defining three controversies. She was curious about the idea of objectivity as requiring value neutrality, how for instance, the value in medical theories were directed by the needs and interests of pharmaceutical companies as opposed to their patients and not people. This is against value neutral. She ascertains that researchers from philosophy, political theory, biology, sociology and psychology should work in parallel in their research and presentations in order to remove the lack of objectivity and the full presence of white elite male class that shape research, the cliché good research characteristics.

Harding in "The feminist standpoint theory reader" (2004) claims that knowledge is always socially situated. Therefore, the dominant group and the oppressed group take on different roles and status, and oppressed groups would subsequently develop their potentials to turn oppressive features into productive ones through critical insight they acquire. As a result, Harding's standpoint theories investigate how "a social and political disadvantage can turn into an epistemological, scientific, and political advantage" (p. 7). Women as the subject of feminism are enabled to produce different types of knowledge specific to their own status, and their knowledge would consequently become central idea of this article. It is also important to note that standpoint theory is not simply a perspective to look at the topic, but rather becomes an active employment of science and politics. In the introduction of the three controversies by Harding, certain questions regarding the first controversy arise: How come science is directed and managed only or primarily by corporation states and militaries?; How do we define the relationship between science and society?; Does science provide all our questions proposed by a small group of scientists or we as the users should contribute in raisin the questions and expressing our concerns.

To implement the above concern, Harding's second site of controversy (2004) determines the importance of staying within the group. This would highlight the fact that in topics concerning women, women have to practice sharing their questions, issues, interests and potentials to investigate the core of the case. This does not eliminate their individual characteristics, however, focusing on the shared important issues would facilitate the emergence of the unique expectations and interests. In addition, many of these characteristics as women's experiences, their social locations and family formations can ground their knowledge and contribute to their cause. In other words, she tries to call attention to the idea that knowledge is always a social product as well as an ending product by individuals. In other words, knowledge is a by-product of two dimensions, and it is not possible to stick to one and eliminate role of the other. They are always located at in certain historical moments, certain geographical places, certain cultures and certain ways in which those cultures and geographies and histories interact. So, knowledge is both intra-individually produced and produced through group experiences. It is also emphasized by Harding in the article "The feminist standpoint theory reader" that women as an oppressed group can practice spotting its distinctive opportunities and turn them to a source of critical thinking about how the dominant society is structured and perceives the world. Therefore, standpoint theory can provide the standing point for women to find the roots of social and political disadvantages and to turn them into an epistemological, scientific, and political advantage. 
Unfortunately, the structure of the world is hierarchical, and things are running based on power relations, still this power enables and limits our visions to subjects. The solutions as recommended by Harding is that dominant group can use it as a resource to investigate issues and to spread the words in the possible manners. Their works would be published in books and magazines or would appear in lectures and speeches. This would become the platform to publicize the issues and concerns of the oppressed group and in our research topic women. To conclude three sites of controversies by Harding, it is important to note that we should always ask whose knowledge is being produced. In the case with feminism, it is important that questions being raised by women who are being affected by rules and policies. It cannot be a sole scientific lab experiment provided by men, but rather a social psychological mainstream which makes the right of women as the product of their own contribution to be taken. However, excluding men as the other half of the society would not add to the value of the research, since their contribution due to different physical appearance, different histories and different social patterns would answer to several questions which are women's concern and curiosity. Harding in her conversation with Hirsch E. \& Olsen G. A. (1995), claims that both dominant and dominated (marginalized) have to reevaluate one's social location as the instrument of the production of knowledge. It becomes a practice that the marginalized group can provide knowledge related to their own concerns and the dominant group would try to think and use resources from their particular position.

This is an ongoing movement, there is still a lot to achieve, and pioneers put so much at risk to determine women's current status. Humans as the citizens of the world all benefit from this movement one way or another, since everybody's knowledge matter today.

\section{Acknowledgment}

This paper is an output of the doctoral level research course named 'Theories of Science and Research Ethics in Education Research' under the supervision of Rosemary Kate Martin (Professor of Arts Education with a focus on Dance and Multiculturalism, Department for Teacher Education) and Stine Helena Bang Svendsen (Associate Professor, Faculty of Social and Educational Science) in fall 2020/spring 2021. They did a tremendous support in narrowing down to my favorite topic.

\section{References}

Beauvoir, S. (2000). The Second Sex, Women as Other. (pp. 1-16)

Butler, J. (1990). Gender Trouble: Feminism and the subversion of identity. $163-180$. Routledge.

Butler, J. (1986). Sex and Gender in Simone de Beauvoir's Second Sex. Yale French Studies. (pp. 35 - 49). Yale University Press

Harding, S. (1998). Women, Science, and Society. Science, 281, 1599 - 1600.

Harding, S. G. (2004). The feminist standpoint theory reader: Intellectual and political controversies. (pp. 1 -17). Routledge 
6-8 August 2021

Budapest, Hungary

Harding, S. (2004). A Socially Relevant Philosophy of Science? Resources from Standpoint Theory's Controversiality. Hypatia, 19(1), 25-47. Retrieved May 6, 2021, from http://www.jstor.org/stable/3810930

Hirsh, E., Olson, G., \& Harding, S. (1995). Starting from Marginalized Lives: A Conversation with Sandra Harding. JAC, 15(2), 193-225. Retrieved May 5, 2021, from http://www.jstor.org/stable/20866024

Williams, R. (1977). Marxism \& Literature. (pp. 75 - 106). Oxford University Press. 